\section{P53 and microRNAs in chronic lymphocytic leukemia}

\author{
Johannes Bloehdorn, ${ }^{1}$ Christian Langer, \\ Hartmut Döhner, ${ }^{1}$ Thorsten Zenz, ${ }^{1,2}$ \\ Stephan Stilgenbauer ${ }^{1}$ \\ ${ }^{1}$ Department of Internal Medicine III, \\ University of UIm, Ulm, Germany \\ 2Department of Translational Oncology, \\ National Center for Tumor Diseases \\ (NCT), Heidelberg, Germany \& \\ Department of Internal Medicine V, \\ University of Heidelberg, Heidelberg, \\ Germany
}

\begin{abstract}
There has been considerable progress in characterising chronic lymphocytic leukemia with respect to the underlying biology and the corresponding clinical presentation. Most patients with CLL live for years without the need for therapy. This does not hold true for patients that exhibit inactivation of the tumour suppressor p53 or, possibly, its pathway members. Deletions of chromosome 17p and mutations of TP53 are the main characteristic of aggressive and refractory disease. In this review we will outline the current understanding of mechanisms known to contribute to dysfunctional p53 and its connection to microRNAs.
\end{abstract}

\section{Introduction}

Chronic lymphocytic leukemia (CLL) is the most frequent leukemia in the western world ${ }^{1}$ characterized by the accumulation of small, non-dividing B-lymphocytes in various lymphatic tissues, the bone marrow and the blood. Novel findings additionally underline the potential impact of the tumourenvironment on disease progression and refractoriness to therapy. Specifically, the interaction with surrounding T-cells and so called nurse-like cells seems to provide anti-apoptotic and proliferative stimuli. ${ }^{2}$

In most cases the patients live for years without symptoms. However, a considerable portion of patients show a more severe or progressive disease course. Extensive research on the underlying mechanisms has dissected this leukemia with respect to epidemiologic data, biology and the heterogeneous clinical presentation. ${ }^{3}$ Nowadays, patients can be stratified to different risk-groups by utilising prognostic markers such as recurrent genomic aberra- tions ${ }^{4}$ and mutational status of TP5 $3^{5}$ or possibly ATM. ${ }^{6}$ The status of somatic mutations in the variable regions of the immunoglobulin heavy chain (IGHV) genes, ${ }^{7,8}$ biased IGHV usage and stereotyped B cell receptors (BCRs) 7,9,10 exhibit important prognostic value as well. Additional insights and potential for risk-stratification came from the discovery of microRNAs (miRs) as key elements of specific gene-regulation. These small non-coding RNAs were shown to modulate the expression and translation of target mRNA and therefore to act as oncogenes or tumour suppressors. ${ }^{11-13}$ Subsequent profiling studies revealed the association with clinical features and prognostic markers. For example, low levels of miR-223 and the miR-29-family were found by independent groups to coincide with unmutated IGHV and disease progression. ${ }^{14-16}$ MiRs gained additional attention when it became evident that p53 shows considerable integration to the miR level. ${ }^{17-20}$ The finding of this new regulatory mechanism extended the understanding of chemotherapy resistance and at the same time offers opportunities to increase the accuracy of risk-stratification and treatment choice. ${ }^{3}$

\section{Role of p53 in cancer}

Impairment of the p53-network by loss or mutation of single components usually results in detrimental effects and has been shown for a variety of cancers.

Though mutations are present in the majority of gastrointestinal- or gynaecological cancers or malignancies of the head and neck ${ }^{21-23}$ mutations in haematological malignancies are found only in approx. $10 \%$ at presentation. ${ }^{24}$

The role of p53 and especially its deregulation has been studied intensively for the last three decades and currently places p53 at the center of a complex regulatory network in tumour suppression. ${ }^{25,26}$ Deleterious signals such as oncogene activation, stress and especially DNA double strand breaks induced by radiation or cytotoxic drugs, result in an orchestrated activation of the ataxia telangiectasia mutated (ATM) pathways ${ }^{27}$ and consecutive increase of p53-activity. ${ }^{28,29}$

Convergence of DNA-damage induced signals to p53 and its negative regulators mouse double minute 2 (MDM2) and mouse double minute 4 (MDM4) facilitates a shift towards a p53 dominance. ${ }^{30,31}$ Induction or repression of genes with p53 response elements mediate elementary functions like induction of apoptosis by BBC3 and BAX encoding the proteins PUMA and BCL-2 associated X, cell cycle arrest through CDKN1A encoding p21 and activation of senescence. ${ }^{26,32-35}$
Correspondence: Johannes Bloehdorn, Department of Internal Medicine III, University of Ulm, Ulm, Germany.

E-mail: stephan.stilgenbauer@uniklinik-ulm.de

Key words: P53, chronic, lymphocytic leukemia.

Received for publication: 21 March 2011.

Revision received: 11 May 2011.

Accepted for publication: 24 May 2011.

This work is licensed under a Creative Commons Attribution NonCommercial 3.0 License (CC BYNC 3.0).

(C) Copyright J. Bloehdorn et al., 2011

Licensee PAGEPress, Italy

Journal of Nucleic Acids Investigation 2011; 2:e8 doi:10.4081/jnai.2011.e8

In 2007 the regulatory network of p53 was extended through the observation that members of the miR-34 family were directly regulated by $p 53$. Up-regulation of these miRs mediated cell cycle arrest and apoptosis by repression of various potential targets including CDK4/6, Cyclin E2, MET and Bcl-2. ${ }^{17-19}$ Furthermore, p53 was shown to be involved in miR-processing, ${ }^{36}$ to increase the own efficacy through a feedback loop via miR-34a and SIRT1 ${ }^{37}$ or to be directly repressed by miRs. ${ }^{38,39}$

\section{Characteristics, clinical presen- tation and therapeutic conse- quences in CLL with p53 path- way defects}

Early evidence for TP53 and ATM involvement in CLL came from the observation of recurring genomic aberrations of chromosome $17 p$ and $11 q$ in the early 90 s and consecutive investigations pointed at the prognostic meaning of loss or mutation of the involved genes, namely TP53 and ATM. ${ }^{5,6,40-43}$

Interestingly, the distribution of these highrisk lesions was found with significant predominance in unmutated IGVH CLL cases. ${ }^{44-47}$ The poor prognosis in cases with unfavourable genomic lesions which show resistance to purine analogues or alkylating agents and rapid disease progression ${ }^{4,5,48-51}$ has led to the development of prognostic models for riskadapted therapy. ${ }^{3}$ Combined treatments including compounds that act independently of ATM and TP53 for example alemtuzumab and possibly lenalidomide as well as flavopiridol are promising in these cases. ${ }^{50,52,53}$

\section{ATM impairment in CLL}

Deletion of chromosome 11q is the second 
most frequent aberration in CLL (15-25\%) and mutations of the ATM gene occur in $36 \%$ of patients with $11 \mathrm{q}$ deletions or $12 \%$ of all patients irrespective of $11 \mathrm{q} \cdot{ }^{4,54,55} 11 \mathrm{q}$ deletions are rarely found in earlier stages whereas advanced CLL patients exhibit this genomic aberration in roughly $25 \% .^{3}$ There are hints that ATM-mutations in 11q deleted cases may evolve during disease progression ${ }^{54,55}$ and biallelic ATM abnormalities therefore might represent a more advanced stage than those with impairment of just a single allele. ${ }^{55}$ ATM mutant tumours show an intermediate to poor clinical course with initial response to treatment but recurring relapse and extensive lymphadenopathy. In vitro these tumours often retain the capacity for apoptosis at a low level after DNA damage ${ }^{56,57}$ However, in contrast to mouse-models with homozygous ATM-disruption and increased radio-sensitivity, ${ }^{58,59} 11 \mathrm{q}$ deleted CLL cells with ATM-mutations have been reported to show a relative radio-resistance $^{56,60}$ implicating additional mechanism in CLL for alternative survival mechanisms and the aggressive phenotype. ${ }^{61-63}$ The clinical course of patients with $11 \mathrm{q}$ deletion and remaining wild-type ATM appears to be better than that of patients with a coexisting mutation of the other ATM allele. ${ }^{55}$ It has been hypothesized that DNA damaging agents in CLL with loss of one allele may provide a selective pressure for the development and proliferation of sub-clones with biallelic ATM defects. ${ }^{54,55}$ Studies showing better results after more intensive combination chemotherapy in these patients ${ }^{63,144,145}$ seem to support this model since the fraction of sub-lethally exposed cells prone to clonal evolution might be diminished in this setting. Further confirming this, novel results show high efficacy for chemo-immunotherapy in patients with $11 \mathrm{q}$ deletions. ${ }^{64,65}$ The addition of rituximab to FCbased regimen was reported with $\mathrm{CR}$ rates more than three times higher than with standard chemotherapy alone ${ }^{64}$ (Figure 1).

\section{TP53 impairment in CLL}

In contrast to $11 \mathrm{q}$ deletions, loss of chromosome $17 p$ belongs to the less frequent aberrations in CLL (approx. 7\% in untreated patients), its association with TP53 mutation is tight and was found to exceed the $80 \%$ rate. Though TP53 mutations are rare in cases with unaffected chromosome $17 \mathrm{p},{ }^{5,66,67}$ a preferential selection of clones bearing single TP53 missense mutations has been suggested for clinically advanced patients with unfavourable risk factors. ${ }^{68}$ In addition, $17 p$ deletions and TP53 mutations have been found to correlate with genomic complexity which itself is associated with short time to initiation of treatment. ${ }^{66,67,69}$ With respect to clinical presenta- tion, 17 p deletions occur in $5-7 \%$ of patients with early stage disease and are present in approximately one third of advanced, refractory cases. ${ }^{5,50}$ The incidence of TP53 mutations ranges between $4-10 \%$ in patients without prior treatment. ${ }^{5,41,66}$ Similar to other cancer entities, TP53 mutations in CLL are found to be mostly missense mutations located in the DNA-binding domain which leads to impaired transcriptional activity of $\mathrm{p} 53 .^{70,71}$ Beside the frequently affected regions (codon 173, 220, 248, and 273), a high incidence of frameshift mutations has been reported for CLL. ${ }^{70,71}$ CLL with abnormality of TP53 is clinically more aggressive, mostly shows primary therapy resistance and lacks DNA damage-induced apoptosis in vitro. Cases with single TP53
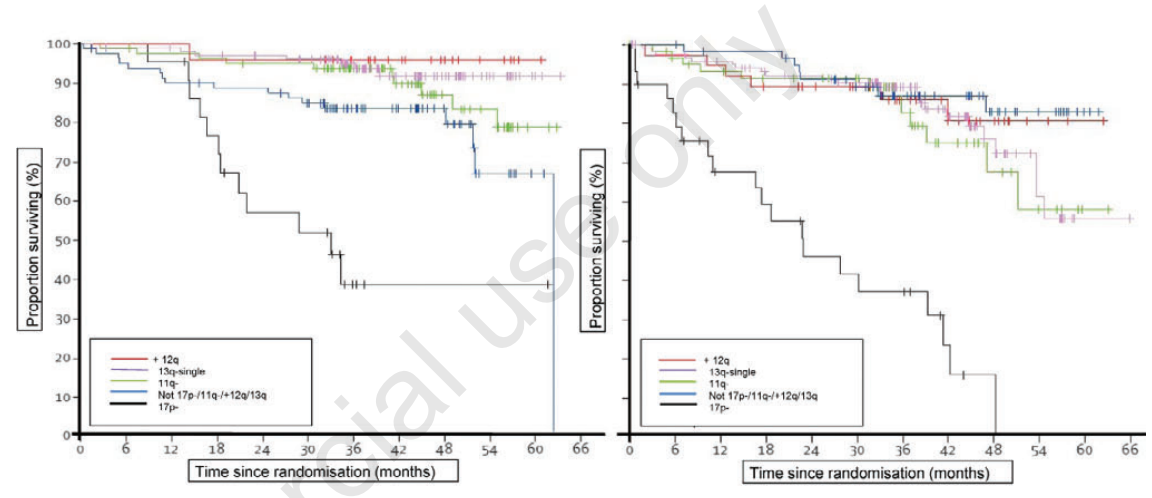

Figure 1. Overall survival (OS) of genetic subgroups in the CLL8 trial (FC vs. FCR) of the German CLLSG: Chemoimmunotherapy (fludarabine, cyclophosphamide and rituximab) (A) and chemotherapy (fludarabine and cyclophosphamide) (B). OS at 3 years for FC vs. FCR after randomisation in prognostic subgroups was: $37 \% v s .38 \%$, including $\operatorname{Del}(17 \mathrm{p})(\mathrm{n}=51) ; 83 \%$ vs. 94\%, including $\operatorname{Del}(11 \mathrm{q})(\mathrm{n}=142) ; 86 \%$ vs. 96\%, including Trisomy $12(\mathrm{n}=61) ; 89 \%$ vs. $95 \%$, including $\operatorname{Del}(13 \mathrm{q})(\mathrm{n}=224) ; 87 \%$ vs. $83 \%$, no abnormalities $(n=138)$. (Adapted from [63]).
A

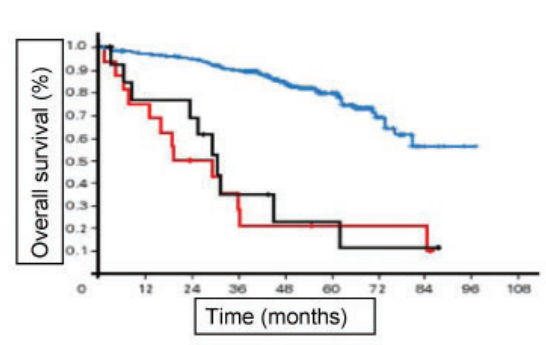

mutations have a clinical course resembling cases with coexisting 17p deletion and mutation of TP53 ${ }^{66,72}$ (Figure 2). Though chemoimmunotherapy based treatments have been found highly effective in CLL, 17p deleted cases do not substantially benefit from this treatment $^{64}$ (Figure 1).

\section{Other pathway members that con- trol p53 function}

Beside mutation and deletion of TP53 or ATM, p53 dysfunction was attributed to MDM2 mediated effects. P53 levels are partly regulated by MDM2 which binds to p53 and promotes its degradation. As a consequence of this function, overexpression of MDM2 was reported to result in p53 impairment. ${ }^{73,74}$ Moreover, overexpres-
Figure 2. Overall and progression-free survival in CLL patients with respect to TP53 mutation. Patients with TP53 mutations without $17 \mathrm{p}$ deletion have an outcome similar to patients with $17 \mathrm{p}$ deletion. (A) Overall survival (OS) of patients with $17 \mathrm{p}$ deletion ( $n=16$; red), patients with sole TP53 mutation $(n=14$; black), and the remaining patients ( $\mathrm{n}=277$; blue). Median OS is significantly shorter for patients with $17 \mathrm{p}$ deletion $(19.2$ months) and sole TP53 mutation (30.2 months) compared with patients without either abnormality (median OS, not reached; $P<.001$ ). (B) Progression-free survival (PFS) of patients with $17 \mathrm{p}$ deletion $(\mathrm{n}=15$; red), patients with sole TP53 mutation (without $17 \mathrm{p}$ deletion; $n=13$; black), and the remaining patients $(n=260$; blue). Median PFS is significantly shorter for patients with $17 \mathrm{p}$ deletion (19.2 months) and sole TP53 mutation (23.3 months) compared with patients without either abnormality (61.8 months; P<.001). (Adapted from [70]). 
sion of MDM2 was found to be associated with a single nucleotide polymorphism in the intronic promoter region at position 309 in the first intron. ${ }^{75}$ The relevance of SNP309 for the clinical course and MDM2 expression in CLL has been addressed by several studies but remains controversial. ${ }^{76-79}$ Therapeutic approaches by inhibition of MDM2 with small molecules, exemplary Nutlin 3a, have been shown to induce apoptosis irrespective of ATM-expression or MDM2-levels, but, as expected, resistance is reported in association with TP53 mutations. ${ }^{77,80}$

\section{Profiling studies of TP53 and ATM induced gene expression}

The advent of profiling techniques enabled the global assessment of ATM and TP53 dependent changes in CLL. Gene expression profiling has previously been successfully applied aiming to decipher constitutively expressed and functionally altered gene-patterns in different cancers. ${ }^{81}$ Several novel discoveries, including the association of ZAP-70 expression and IGHV mutation status and its prognostic value became possible by using this method. ${ }^{82,83}$ Profiling studies on CLL with mutated or wildtype TP53 or ATM found indistinguishable gene expression patterns for unmanipulated cells while radiation induced changes enabled clear differentiation. Only approximately one third of the genes induced by ATM upon radiation showed changes in a p53 specific manner and were mainly related to apoptosis and cell-cycle regulation while the remaining and therefore ATM-dependent genes were rather involved in promoting cell survival and suppressed if TP53 was unattenuated. ${ }^{60}$

Dynamic changes in CLL cells after fludarabine treatment confirmed specific TP53- and time-dependent changes in CLL similar to gamma-irradiation but were absent in fludarabine resistant cases. ${ }^{84}$ Discrepant observations come form another study investigating central genes involved in the regulation of apoptosis, cell cycle, B-cell activation and BCR signalling showing significant deregulation in cases with $17 p$ deletion for genes not specifically located on 17p, moreover this study found ATM to be significantly reduced in $17 \mathrm{p}$ deleted cases ${ }^{85}$ and therefore supports the hypothesis of related pathogenic pathways involving a common mechanism that leads to ATM inactivation. ${ }^{56,60,85}$

In summary, alterations affecting TP53 occur in $40-50 \%$ of refractory cases and the remaining fraction exhibits deletions of $11 \mathrm{q}$ only in 20-30\% indicating additional mechanisms leading to resistance. ${ }^{3,55,66,72}$ Regardless of future options or additional effects that can be achieved with combination therapies, allogeneic stem cell transplantation currently stays the only treatment with potential for cure. ${ }^{86}$ Promising approaches may be derived from the observation that genetic alterations in tumours display specific dependencies and therefore might be selectively used as targets. This circumstance has been used to simulate the synthetic lethal interaction for p53-deficient settings in which consecutive suppression of ATM strongly sensitized tumours to DNA-damaging chemotherapy. ${ }^{87}$

\section{Connecting the p53 pathway and microRNAs in CLL}

\section{Karyotype-dependent changes}

MiRs have been found to contribute to initiation, progression, outcome and clinical characteristics in CLL. ${ }^{88}$ Studies investigating expression patterns with regard to specific subgroups found deregulation of single miRs in CLL and especially miR-expression with respect to cytogenetic subgroups revealed significant overlap. Strong association with a specific karyotype, even in cases with coexisting other deletions, was found in one study by utilising miR-155, miR-29b, miR-151-3p, miR-29c, miR-34a, miR-640, miR-148a, miR-146a and miR-146b-5p which were identified and confirmed by using gene expression analysis and qRT-PCR (Table 1). ${ }^{89}$

Specific patterns were confirmed for groups with $17 \mathrm{p}^{89-91}$ and $11 \mathrm{q}$ deletion (Table 1). ${ }^{16,89,92}$ It is interesting that the validated miRs, discriminating cytogenetic groups, do not necessarily map to the deleted regions ${ }^{89}$ and one might therefore suspect the genes located in these regions to be involved in miR-regulatory circuits.

One example is miR-34a which maps to chromosome locus 1p36 and shows low expression levels in 17p deleted cases. Evidence for the role of p53 in regulating miRs came from several studies that found the members of the miR-34 family to be directly induced by p53. MiR-34a mediates essential steps in a p53dependant manner by targeting specific genes involved in the cell-cycle, G1-arrest, proliferation and apoptosis. ${ }^{17-20,93}$

Table 1. MicroRNA expression with respect to $17 \mathrm{p}$ or $11 \mathrm{q}$ deletion, mutation of TP53 and overexpression/knockdown of TP53.

\begin{tabular}{lll}
\hline Characteristic & Differentially expressed miRs & Study/Author \\
$\begin{array}{ll}\text { 17p-deletion (including TP53 } \\
\text { mutations/knockdown) }\end{array}$ & miR-151-3p, miR-29c, miR-34a (down) & Visone 2009 \\
& $\begin{array}{l}\text { miR-21, miR-155, miR-15a (up) } \\
\text { miR-34a, miR-181b (down) }\end{array}$ & Rossi 2010 \\
& miR-34a, miR-29c, miR-17-5p (down) & Mraz 2009 \\
TP53 overexpression & miR-34b (up) & Fabbri 2011 \\
\hline 11q-deletion & miR-29b (down), miR-155 (up) & Visone 2009 \\
& miR-29, miR-181 (down) & Pekarsky 2006 \\
& miR-34b, miR-34c (down) & Fabbri 2011 \\
\hline
\end{tabular}

\section{MiR-34a}

The p53-dependence has been proven for miR-34a in the disease specific context of CLL. Cases with 17p deletion or mutation of TP53 were shown to exhibit significantly lower basal levels ${ }^{90,91,94-96}$ and miR-34a was downregulated after transfection with siRNA against TP53 in MEG01 cells. ${ }^{91}$

Further confirming the dependence between TP53 and miR-34a, irradiation in the absence of functional p53 did not increase expression. In line with the role as a functional member of the p53-pathway, low levels of miR-34a were found in association with fludarabine-refractory disease, impaired DNAdamage response and resistance to apoptosis in cases with unaffected 17p or TP53. It is important to emphasize that no association with the 11q-status was detectable since low miR-34a levels were equally distributed between cases with and without 11q-deletion. ${ }^{95}$ However, this finding was not confirmed in a following investigation where cases with affected ATM were attributed to cause low miR-34a levels. $^{96}$

Since mir-34a maps to the chromosomelocus 1 p36 which is deleted in a variety of malignancies including neuroblastomas, cancers of the gastrointestinal tract and the breast, similar changes would be expected for CLL but have not been reported up to now. ${ }^{97-102}$ Other mechanisms leading to the deregulation of microRNAs have been found in epigenetic changes. Low levels of miR-34a that are not caused by 17p deletion or TP53 mutation may result from aberrant $\mathrm{CpG}$ methylation which has been shown in other cancers. ${ }^{103}$ With respect to its biologic function, additional regard has to be paid to the observation that miR-34a is significantly up-regulated together with p21 and PUMA in a B-CLL mouse-model during the transition from pre-leukemic to leukemic phase which suggests an oncogenic activation of the p53-pathway. ${ }^{95,96}$ The fact that miR-34a levels are upregulated in steady state both in cases with good $\mathrm{d}^{95}$ and adverse risk features and especially in comparison with healthy B-cells ${ }^{96}$ implicates the possibility that 
miR-34a needs to act in concert with p21, Bax and Puma to execute its function after DNA damage. ${ }^{95}$ Constituting a putative therapeutic option, investigations using overexpression of miR-34a have confirmed the potential by inducing apoptosis in various cancer models ${ }^{104}$ ${ }^{106}$ including CLL $^{96}$ which exposes it as attractive candidate for future investigations. Still, miR-34a effects in the context of p53-pathway alterations remain to be specifically investigated due to the supposed feedback on regulators upstream of p53 itself ${ }^{1737}$ (Figure 3).

\section{$\mathrm{MiR}-34 \mathrm{~b} / \mathrm{c}$}

Unlike the confirmed impact of miR-34a, the role of the miR-cluster $34 \mathrm{~b} / \mathrm{c}$ remains less well defined in the context of the p53-pathway. Contrasting previous observations, ${ }^{17-20} \mathrm{miR}$ $34 \mathrm{~b} / \mathrm{c}$ expression in CLL was unaffected upon p53 activation ${ }^{95}$ while another study found TP53 to bind a pre-miR-34b/c site on chromosome 11 with significant transactivation effect and miR-34b induction after TP53-transfection of MEG01 cells. ${ }^{93}$ Furthermore, the miR-34b/c cluster on chromosome region 11q23 centromeric to ATM is frequently deleted in $\mathrm{CLL}^{4}$ and current studies draw a heterogeneous picture with respect to karyotype-specific expression levels. ${ }^{89,93}$ Reasons for variance in expression might include differences in cohort size, biological characteristics, clinical stage or epigenetic regulation and should be carefully addressed in future investigations.

The tempting connection between 11q deletion and loss of negative regulators mapping to this region remains in focus of research. As TCL1 is overexpressed in 11q deleted CLL one group investigated complementarity of the miR-34b/c cluster members to this genes sequence. MiR-34b* also known as miR-34b-5p was found to match on 4 different positions and to act as specific regulator of TCL1 in HEK293T cells. ${ }^{107}$ More recently the miR-34 family has been proposed as regulators of ZAP 70 with interconnection to TP53, cytogenetics and a newly identified regulatory feedback mechanism between TP53 and the miR15a/16-1 cluster. ${ }^{93}$

\section{MiR-15a/16-1}

MiR-15a and miR-16-1 were identified as part of the tumour suppressor mechanism that has been suspected at the minimally deleted region (MDR) on chromosome 13q14 and following research unmasked their role as repressors of BCL-2. ${ }^{108,109}$ Both miRs have been found to inversely correlate with BCL-2 protein levels in CLL with increased rates of apoptosis after transfection with wild-type miR-15/16. ${ }^{109}$

A recent study revealed a direct feedback of miR-15a/16-1 on TP53 and vice versa. Overexpression of miR-15a and 16-1 resulted in significant reduction of p53 in MEG01 cells and primary CLL (with consecutive reduction of CDKN1A, BBC3 and BCL2). Additionally, p53 was confirmed to induce the miR-15a/16-1 cluster through specific upstream binding sites. The observation of high TP53 mRNA and protein expression in CLL cases with bi- or monoallelic $13 q$ deletion compared with normal karyotype cases supports this finding in primary samples. ${ }^{93}$ However, the functional meaning of previously observed high miR-15a levels in patients with $17 p$ deletion remains to be further elucidated in this context. ${ }^{91}$

\section{MiR-29 and miR-181}

TCL1 was previously shown to result in CLL when overexpressed in murine B cells ${ }^{110}$ and to positively regulate $\mathrm{AKT}^{111}$ which itself restrains activity of p53 by activating MDM2. The fact that miRs-29 and miRs-181, which specifically target TCL1, ${ }^{16,92}$ are downregulated in cases with $11 q / 17$ p deletion and aggressive CLL $^{16,89-92}$ implicates an interconnection to the functionality of the p53-pathway. However, it remains unknown how these miRs are regulated and if ATM or TP53 play a specific role in this context.

In line with this, the miR-29 family was shown to influence the p53-pathway by targeting CDC42 which itself reduces p53 levels ${ }^{112}$ and by regulating $\mathrm{p} 85 \alpha$ which composes the regulatory subunit of PI3K. Reducing activity of PI3K with consecutively lower phosphorylation of downstream targets like AKT and MDM2 therefore stabilises p53. ${ }^{112}$

\section{MiR-155}

MiR-155 is upregualted in lymphomas of Band T-cell origin ${ }^{113,114}$ and shows high expression in CLL compared to normal CD $19^{+} \mathrm{B}$ cells. ${ }^{15}$ Mouse-models with forced expression of miR-155 in B-cell precursors develop a preB-lymphoproliferative disease that progresses to a B-cell malignancy ${ }^{115}$ probably through down-regulation of Ship and C/EBP $\beta .^{116}$ Ship represents a major target of mir- $155^{116,117}$ and negatively regulates the activity of PI3K effectors such as AKT, which is derepressed in T-cell lymphoma with elevated miR-155 levels. ${ }^{114}$ Concomitant deletion of PTEN and SHIP in Bcells was shown to results in spontaneous and lethal mature B cell neoplasm in mouse-models. $^{118}$

The regulation of miR-155 expression has been attributed to transcription-factors including NFkB, AP1 and MYB. ${ }^{19,120}$ Moreover, miR155 has been found upregulated in CLL after TP53 knockdown, in cases with TP53 mutation/ $17 p$-deletion ${ }^{91}$ and in cases with $11 q$ deletion. ${ }^{89}$ Further hints to an interconnection with p53 come from previous studies that report miR155 to be transcriptionally repressed in a p53- dependent manner ${ }^{121}$ and that it executes repression on the Tumour Protein 53-Induced Nuclear Protein 1 (TP53INP1) which itself is a pro-apoptotic gene downstream of p53. ${ }^{122}$

\section{MiR-21}

Mir-21 is a classic example of oncogenic acting miRs in cancer and has been frequently found overexpressed in a variety of malignancies $^{114,123-128}$ including CLL. ${ }^{13,15,91}$

Its potential for the development of lymphomas has been shown in vivo in a mouse model that conditionally expressed miR-21 and developed a pre-B malignant lymphoid-like phenotype with involvement of lymphoid organs. ${ }^{129}$ Interestingly knockdown or loss of miR-21 revert impaired apoptosis, proliferation and decrease tumourigenesis. ${ }^{130}$ Amongst the confirmed targets are the tumoursuppressors CDC25A ${ }^{131}$, PDCD4, ${ }^{114,132,133}$ BTG2 $^{134}$ and

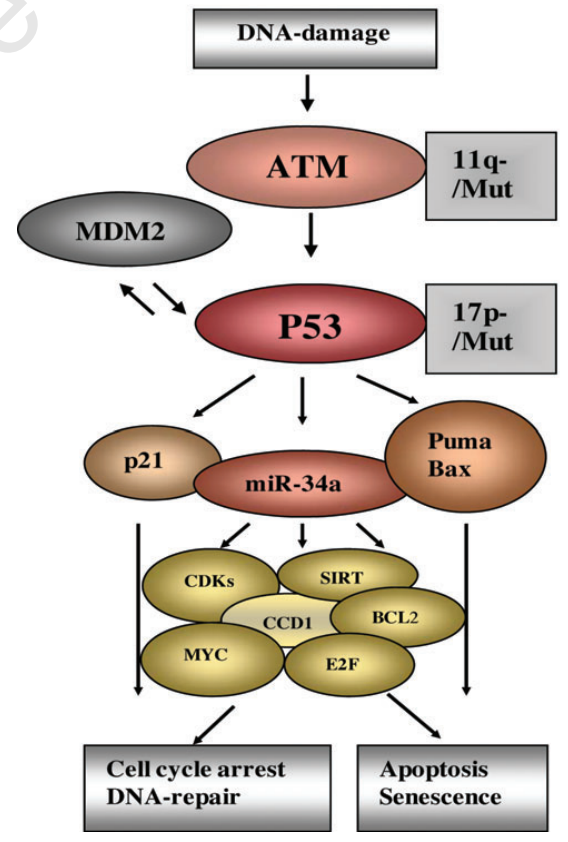

Figure 3. Schematic model for the p53miR-34a pathway. P53 is activated by DNAdamage through ATM. Consecutive activation of p21, Puma and Bax enable cell cycle arrest, DNA-repair, senescence and programmed cell death through apoptosis. MiR-34a is a direct transcriptional target of p53 and upregulated upon activation of p53. Cell cycle arrest and apoptosis mediated by $\mathrm{p} 21$ and Puma/Bax are fostered by the downregulation of genes targeted by miR34a. Disruption of this hierarchial model may result from loss or mutation of ATM or TP53 or alterations (overexpression and SNP309) of MDM2. Of note, miR-34a downregulation may occur independently of p53 in activation in CLL and is associated with resistant disease. 


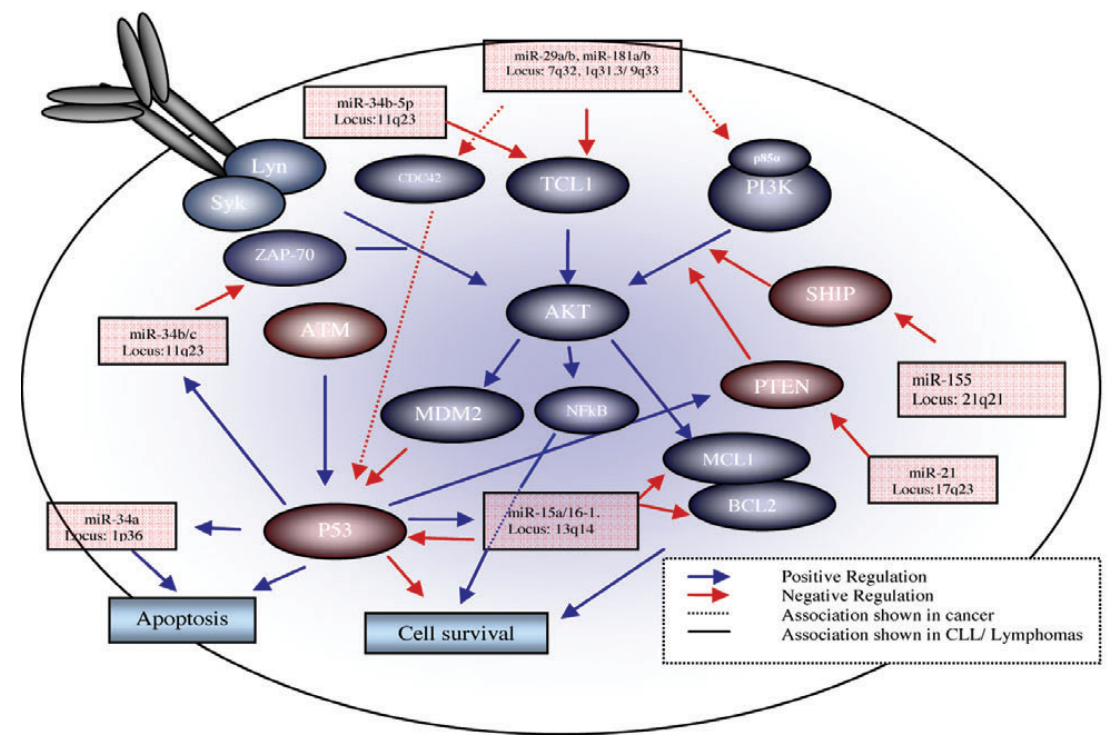

Figure 4. Role of deregulated microRNAs in CLL with impaired p53-pathway. Altered microRNA levels confer survival and growth advantage by loss of tumor suppressive or gain of oncogenic function. MiR-34a is downregulated in CLL with $17 \mathrm{p}$ deletion or TP53 mutation. P53 is the major transcriptional regulator of miR-34a. Beside p21, Bax and other it composes an important mediator of the p53-effects like cell-cycle arrest and apoptosis. $M i R$ $34 \mathrm{~b}$ and $\mathrm{c}$ are regulated by $\mathrm{p} 53$ and were recently shown to target ZAP-70 in CLL. MiR-34b* (also known as miR-34b-5p) targets TCL1. The miRs-34b, 34b-5p and 34c are located on chromosome 11q which is frequently lost in CLL. TCL1 is upregulated in 11q deleted CLL and has been attributed to the loss of a negative regulator in this region. TCL1 is a direct target of miR-29 and 181 which are downregulated in aggressive and $11 \mathrm{q} / 17 \mathrm{p}$ deleted CLL. Moreover the miR-29 family targets CDC42 and the regulatory subunit of PI3K, namely $\mathrm{p} 85 \alpha$. MiR-15a/16-1 is located on chromosome $13 \mathrm{q} 14$ which most frequently shows aberrations in CLL. Feedback regulation conferred by repression of TP53 through $m i R-15 \mathrm{a} / 16$ 1 and their induction through p53 has been recently reported in CLL. Both miRs were shown to target antiapoptotic genes like BCL2 and MCL1. MiR-155 and miR-21 are overexpressed in lymphomas and target PTEN and SHIP. Impairment of PTEN has been found in several malignancies. PTEN and SHIP collectively suppress PI3K/AKT signalling and concomitant deletion of PTEN and SHIP in B-cells results in spontaneous and lethal mature $B$ cell neoplasms in mouse-models.

PTEN. ${ }^{114,135}$ The fact that the above listed miR21 regulated genes are either downstream targets of p53, interact with the p53-pathway or regulate the cell cycle ${ }^{132,136-139}$ accentuates a putative role as a modulator of $\mathrm{p} 53$ function in CLL. Especially PTEN, which is a negative regulator of PI3K-signalling and shows tight interaction with $\mathrm{p} 53,{ }^{137,140,141}$ represents an important miR-21 target with relevance in CLL ${ }^{142,143}$.

Taken together, microRNA deregulation in CLL with impaired p53-pathway seems to confer advantages mostly by impaired apoptosis and increased survival due to loss of tumour suppressive or gain of oncogenic potential. Moreover it is suggestive that the deregulated microRNAs act in concert to additionally impair activity of p53 (Figure 4). Further systemic models as exemplary investigated by Fabbri et al. will lead to a better understanding of pathogenesis and explanation of disease characteristics in CLL with a dysfunctional p53-pathway.

\section{References}

1. Dores GM, Anderson WF, Curtis RE, et al. Chronic lymphocytic leukaemia and small lymphocytic lymphoma: overview of the descriptive epidemiology. Br J Haematol 2007;139:809-19.

2. Burger JA, Ghia P, Rosenwald A, Caligaris-Cappio F. The microenvironment in mature B-cell malignancies: a target for new treatment strategies. Blood 2009;114:3367-75.

3. Zenz T, Mertens D, Küppers R, et al. From phocytic leukaemia. Nat Rev Cancer 2010; 10:37-50.

4. Döhner H, Stilgenbauer S, Benner A, et al. Genomic aberrations and survival in chronic lymphocytic leukemia. N Engl J Med, 2000;343:1910-6.

5. Döhner H, Fischer K, Bentz M, et al. p53 gene deletion predicts for poor survival and non-response to therapy with purine pathogenesis to treatment of chronic lym- analogs in chronic B-cell leukemias. Blood 1995;85:1580-9.

6. Schaffner C, Stilgenbauer S, Rappold GA et al. Somatic ATM mutations indicate a pathogenic role of ATM in B-cell chronic lymphocytic leukemia. Blood 1999;94:74853.

7. Fais F, Ghiotto F, Hashimoto $\mathrm{S}$, et al. Chronic lymphocytic leukemia B cells express restricted sets of mutated and unmutated antigen receptors. J Clin Invest 1998;102:1515-25.

8. Hamblin TJ, Davis Z, Gardiner A, et al. Unmutated $\operatorname{Ig} \mathrm{V}(\mathrm{H})$ genes are associated with a more aggressive form of chronic lymphocytic leukemia. Blood 1999;94: 1848-54.

9. Tobin G, Thunberg U, Johnson A, et al. Chronic lymphocytic leukemias utilizing the VH3-21 gene display highly restricted Vlambda2-14 gene use and homologous CDR3s: implicating recognition of a common antigen epitope. Blood 2003;101: 4952-7.

10. Stamatopoulos K, Belessi C, Moreno C, et al. Over $20 \%$ of patients with chronic lymphocytic leukemia carry stereotyped receptors: Pathogenetic implications and clinical correlations. Blood 2007;10:25970 .

11. Landgraf P, Rusu M, Sheridan R, et al. A mammalian microRNA expression atlas based on small RNA library sequencing. Cell 2007;129:1401-14.

12. Calin GA, Pekarsky Y, Croce CM. The role of microRNA and other non-coding RNA in the pathogenesis of chronic lymphocytic leukemia. Best Pract Res Clin Haematol 2007;20:425-37.

13. Calin GA, Liu CG, Sevignani C, et al., MicroRNA profiling reveals distinct signatures in B cell chronic lymphocytic leukemias. Proc Natl Acad Sci USA 2004;101:11755-60.

14. Calin GA, Ferracin M, Cimmino A, et al. A MicroRNA signature associated with prognosis and progression in chronic lymphocytic leukemia. N Engl J Med 2005; 353:1793-801.

15. Fulci V, Chiaretti S, Goldoni M, et al. Quantitative technologies establish a novel microRNA profile of chronic lymphocytic leukemia. Blood 2007;109:494451.

16. Stamatopoulos, B., et al., microRNA-29c and microRNA-223 down-regulation has in vivo significance in chronic lymphocytic leukemia and improves disease risk stratification. Blood 2009;113:5237-45.

17. Chang TC, Wentzel EA, Kent OA, et al. Transactivation of miR-34a by p53 broadly influences gene expression and promotes apoptosis. Mol Cell 2007;26:745-52.

18. He L, He X, Lim LP, et al. A microRNA com- 
ponent of the p53 tumour suppressor network. Nature 2007;447:1130-4.

19. Raver-Shapira N, Marciano E, Meiri E, et al. Transcriptional activation of miR-34a contributes to p53-mediated apoptosis. Mol Cell 2007;26:731-43.

20. Tarasov V, Jung P, Verdoodt B, et al. Differential regulation of microRNAs by p53 revealed by massively parallel sequencing: miR-34a is a p53 target that induces apoptosis and G1-arrest. Cell Cycle 2007;6:1586-93.

21. Blons H, Laurent-Puig P. Laurent-Puig, TP53 and head and neck neoplasms. Hum Mutat 2003;21:252-7.

22. Schuijer M, Berns EM. TP53 mutation in colorectal cancer. Hum Mutat 2003;21:271-6.

23. Schuijer M, Berns EM. TP53 and ovarian cancer. Hum Mutat 2003;21:285-91.

24. Peller S, Rotter V. TP53 in hematological cancer: low incidence of mutations with significant clinical relevance. Hum Mutat 2003;21:277-84.

25. Vogelstein B, Lane D, Levine AJ. Surfing the p53 network. Nature 2000;408:307-10.

26. Vousden KH, Lane DP. p53 in health and disease. Nat Rev Mol Cell Biol 2007;8:27583.

27. Khanna KK, Jackson SP. DNA doublestrand breaks: signaling, repair and the cancer connection. Nat Genet 2001;27:247-54.

28. Kruse JP, Gu W. SnapShot: p53 posttranslational modifications. Cell 2008;133:93030.el.

29. Appella E, Anderson CW. Post-translational modifications and activation of p53 by genotoxic stresses. Eur J Biochem 2001;268:2764-72.

30. Candeias MM, Malbert-Colas L, Powell DJ, et al. P53 mRNA controls p53 activity by managing Mdm2 functions. Nat Cell Biol 2008;10:1098-105.

31. Marine JC, Francoz S, Maetens M, et al. Keeping p53 in check: essential and synergistic functions of Mdm2 and Mdm4. Cell Death Differ 2006;13:927-34.

32. Riley T, Sontag E, Chen P, Levine A. Transcriptional control of human p53-regulated genes. Nat Rev Mol Cell Biol 2008;9:402-12.

33. d'Adda di Fagagna F. Living on a break: cellular senescence as a DNA-damage response. Nat Rev Cancer 2008;8:512-22.

34. Halazonetis TD, Gorgoulis VG, Bartek J. An oncogene-induced DNA damage model for cancer development. Science 2008;319:1352-5.

35. Kastan MB, Zhan Q, el-Deiry WS, et al. A mammalian cell cycle checkpoint pathway utilizing p53 and GADD45 is defective in ataxia-telangiectasia. Cell 1992;71:58797.
36. Suzuki HI, Yamagata K, Sugimoto K, et al. Modulation of microRNA processing by p53. Nature 2009;460;529-33.

37. Yamakuchi M, Ferlito M, Lowenstein CJ. miR-34a repression of SIRT1 regulates apoptosis. Proc Natl Acad Sci USA 2008; 105:13421-6.

38. Hu W, Chan CS, Wu R, et al. Negative regulation of tumor suppressor p53 by microRNA miR-504. Mol Cell 2011;38:68999.

39. Le MT, Teh C, Shyh-Chang N, et al. MicroRNA-125b is a novel negative regulator of p53. Genes Dev 2009;23:862-76.

40. Gaidano G, Ballerini P, Gong JZ, et al. p53 mutations in human lymphoid malignancies: association with Burkitt lymphoma and chronic lymphocytic leukemia. Proc Natl Acad Sci USA 1991;88:5413-7.

41. el Rouby S, Thomas A, Costin D, et al. p53 gene mutation in B-cell chronic lymphocytic leukemia is associated with drug resistance and is independent of MDR1/MDR3 gene expression. Blood 1993;82:3452-9.

42. Döhner H, Stilgenbauer S, James MR, et al. 11q deletions identify a new subset of B-cell chronic lymphocytic leukemia characterized by extensive nodal involvement and inferior prognosis. Blood 1997;89: 2516-22.

43. Bullrich F, Rasio D, Kitada S, et al. ATM mutations in B-cell chronic lymphocytic leukemia. Cancer Res 1999;59:24-7.

44. Kröber A, Seiler T, Benner A, et al. V(H) mutation status, CD38 expression level, genomic aberrations, and survival in chronic lymphocytic leukemia. Blood 2002;100: 1410-6.

45. Oscier DG, Thompsett A, Zhu D, Stevenson FK. Differential rates of somatic hypermutation in $\mathrm{V}(\mathrm{H})$ genes among subsets of chronic lymphocytic leukemia defined by chromosomal abnormalities. Blood 1997;89:4153-60.

46. Stilgenbauer S, Sander S, Bullinger L, et al. Clonal evolution in chronic lymphocytic leukemia: acquisition of high-risk genomic aberrations associated with unmutated $\mathrm{VH}$, resistance to therapy, and short survival. Haematologica 2007;92:1242-5.

47. Shanafelt TD, Witzig TE, Fink SR, et al. Prospective evaluation of clonal evolution during long-term follow-up of patients with untreated early-stage chronic lymphocytic leukemia. J Clin Oncol 2006;24:4634-41.

48. Zenz T, Häbe S, Denzel T, et al. Detailed analysis of p53 pathway defects in fludarabine-refractory chronic lymphocytic leukemia (CLL): dissecting the contribution of 17p deletion, TP53 mutation, p53p21 dysfunction, and miR34a in a prospective clinical trial. Blood 2009;114: 2589-97.

49. Zenz T, Benner A, Döhner H, Stilgenbauer S. Chronic lymphocytic leukemia and treatment resistance in cancer: the role of the p53 pathway. Cell Cycle 2008;7:3810-4.

50. Grever MR, Lucas DM, Dewald GW, et al., Comprehensive assessment of genetic and molecular features predicting outcome in patients with chronic lymphocytic leukemia: results from the US Intergroup Phase III Trial E2997. J Clin Oncol 2007;25:799-804.

51. Catovsky D, Richards S, Matutes E, et al. Assessment of fludarabine plus cyclophosphamide for patients with chronic lymphocytic leukaemia (the LRF CLL4 Trial): a randomised controlled trial. Lancet 2007;370:230-9.

52. Pettitt AR, Matutes E, Oscier D. Alemtuzumab in combination with highdose methylprednisolone is a logical, feasible and highly active therapeutic regimen in chronic lymphocytic leukaemia patients with p53 defects. Leukemia 2006;20:1441-5.

53. Stilgenbauer S, Zenz T, Winkler D, et al. Subcutaneous alemtuzumab in fludarabine-refractory chronic lymphocytic leukemia: clinical results and prognostic marker analyses from the CLL2H study of the German Chronic Lymphocytic Leukemia Study Group. J Clin Oncol 2009; 27:3994-4001.

54. Austen B, Powell JE, Alvi A, et al. Mutations in the ATM gene lead to impaired overall and treatment-free survival that is independent of IGVH mutation status in patients with B-CLL. Blood 2005;106:3175-82.

55. Austen B, Skowronska A, Baker C, et al. Mutation status of the residual ATM allele is an important determinant of the cellular response to chemotherapy and survival in patients with chronic lymphocytic leukemia containing an 11q deletion. J Clin Oncol 2007;25:5448-57.

56. Pettitt AR, Sherrington PD, Stewart G, et al. p53 dysfunction in B-cell chronic lymphocytic leukemia: inactivation of ATM as an alternative to TP53 mutation. Blood 2001;98:814-22.

57. Stankovic T, Stewart GS, Fegan C, et al. Ataxia telangiectasia mutated-deficient B-cell chronic lymphocytic leukemia occurs in pregerminal center cells and results in defective damage response and unrepaired chromosome damage. Blood 2002;99:300-9.

58. Shiloh Y, Tabor E, Becker Y. Abnormal response of ataxia-telangiectasia cells to agents that break the deoxyribose moiety of DNA via a targeted free radical mechanism. Carcinogenesis 1983;4:1317-22. 
59. Barlow C, Hirotsune S, Paylor R, et al., Atm-deficient mice: a paradigm of ataxia telangiectasia. Cell 1996;86:159-71.

60. Stankovic T, Hubank M, Cronin D, et al. Microarray analysis reveals that TP53and ATM-mutant B-CLLs share a defect in activating proapoptotic responses after DNA damage but are distinguished by major differences in activating prosurvival responses. Blood 2004;103:291-300.

61. Stilgenbauer S, Liebisch P, James MR, et al. Molecular cytogenetic delineation of a novel critical genomic region in chromosome bands 11q22.3-923.1 in lymphoproliferative disorders. Proc Natl Acad Sci U S A 1996;93:11837-41.

62. Auer RL, Starczynski J, McElwaine S, et al. Identification of a potential role for POU2AF1 and BTG4 in the deletion of 11 q23 in chronic lymphocytic leukemia. Genes Chromosomes Cancer 2005;43:110.

63. Kalla C, Scheuermann MO, Kube I, et al. Analysis of 11q22-q23 deletion target genes in B-cell chronic lymphocytic leukaemia: evidence for a pathogenic role of NPAT, CUL5, and PPP2R1B. Eur J Cancer 2007;43:1328-35.

64. Hallek M, Fischer K, Fingerle-Rowson G, et al. Addition of rituximab to fludarabine and cyclophosphamide in patients with chronic lymphocytic leukaemia: a randomised, open-label, phase 3 trial. Lancet 2010;376:1164-74.

65. Tsimberidou AM, Tam C, Abruzzo LV, et al. Chemoimmunotherapy may overcome the adverse prognostic significance of $11 \mathrm{q}$ deletion in previously untreated patients with chronic lymphocytic leukemia. Cancer 2009;115:373-80.

66. Zenz T, Kröber A, Scherer $\mathrm{K}$, et al. Monoallelic TP53 inactivation is associated with poor prognosis in chronic lymphocytic leukemia: results from a detailed genetic characterization with long-term follow-up. Blood 2008;112:3322-9.

67. Dicker F, Herholz H, Schnittger S, et al. The detection of TP53 mutations in chronic lymphocytic leukemia independently predicts rapid disease progression and is highly correlated with a complex aberrant karyotype. Leukemia 2009;23:117-24

68. Malcikova J, Smardova J, Rocnova L, et al. Monoallelic and biallelic inactivation of TP53 gene in chronic lymphocytic leukemia: selection, impact on survival, and response to DNA damage. Blood 2009;114;5307-14.

69. Kujawski L, Ouillette P, Erba H, et al. Genomic complexity identifies patients with aggressive chronic lymphocytic leukemia. Blood 2008;112:1993-2003.

70. Zenz T, Vollmer D, Trbusek M, et al. TP53 mutation profile in chronic lymphocytic leukemia: evidence for a disease specific profile from a comprehensive analysis of 268 mutations. Leukemia 2011;24:2072-9.

71. Rossi D, Cerri M, Deambrogi C, et al. The prognostic value of TP53 mutations in chronic lymphocytic leukemia is independent of Del17p13: implications for overall survival and chemorefractoriness. Clin Cancer Res 2009;15:995-1004.

72. Zenz T, Eichhorst B, Busch R, et al. TP53 mutation and survival in chronic lymphocytic leukemia. J Clin Oncol 2010;28: 4473-9.

73. Haidar MA, El-Hajj H, Bueso-Ramos CE, et al. Expression profile of MDM-2 proteins in chronic lymphocytic leukemia and their clinical relevance. Am J Hematol 1997;54:189-95.

74. Koníková E, Kusenda J. Altered expression of p53 and MDM2 proteins in hematological malignancies. Neoplasma 2003;50:31-40.

75. Bond GL, Hu W, Bond EE, et al. A single nucleotide polymorphism in the MDM2 promoter attenuates the p53 tumor suppressor pathway and accelerates tumor formation in humans. Cell 2004;119:591602 .

76. Gryshchenko I, Hofbauer S, Stoecher M, et al. MDM2 SNP309 is associated with poor outcome in B-cell chronic lymphocytic leukemia. J Clin Oncol 2008;26:2252-7.

77. Saddler C, Ouillette P, Kujawski L, et al. Comprehensive biomarker and genomic analysis identifies p53 status as the major determinant of response to MDM2 inhibitors in chronic lymphocytic leukemia. Blood 2008;111:1584-93.

78. Seyfried I, Hofbauer S, Stoecher M, et al. SNP309 as predictor for sensitivity of CLL cells to the MDM2 inhibitor nutlin-3a. Blood 2008;112;2168; author reply 2169.

79. Zenz T, Häbe $\mathrm{S}$, Benner $\mathrm{A}$, et al. The MDM2 -309 T/G promoter single nucleotide polymorphism does not alter disease characteristics in chronic lymphocytic leukemia. Haematologica 2008;93:1111-3.

80. Kojima K, Konopleva M, McQueen T, et al. Mdm2 inhibitor Nutlin-3a induces p53mediated apoptosis by transcriptiondependent and transcription-independent mechanisms and may overcome Atmmediated resistance to fludarabine in chronic lymphocytic leukemia. Blood 2006;108:993-1000.

81. Quackenbush J. Microarray analysis and tumor classification. N Engl J Med 2006;354:2463-72.

82. Klein U, Tu Y, Stolovitzky GA, Mattioli M, et al. Gene expression profiling of B cell chronic lymphocytic leukemia reveals a homogeneous phenotype related to mem- ory B cells. J Exp Med 2001;194:1625-38.

83. Rosenwald A, Alizadeh AA, Widhopf G, et al. Relation of gene expression phenotype to immunoglobulin mutation genotype in B cell chronic lymphocytic leukemia. J Exp Med 2001;194:1639-47.

84. Rosenwald A, Chuang EY, Davis RE, et al. Fludarabine treatment of patients with chronic lymphocytic leukemia induces a p53-dependent gene expression response. Blood 2004;104:1428-34.

85. Kienle DL, Korz C, Hosch B, et al. Evidence for distinct pathomechanisms in genetic subgroups of chronic lymphocytic leukemia revealed by quantitative expression analysis of cell cycle, activation, and apoptosis-associated genes. J Clin Oncol 2005;23:3780-92.

86. Schetelig J, van Biezen A, Brand R, et al. Allogeneic hematopoietic stem-cell transplantation for chronic lymphocytic leukemia with $17 p$ deletion: a retrospective European Group for Blood and Marrow Transplantation analysis. J Clin Oncol 2008;26:5094-100.

87. Jiang H, Reinhardt HC, Bartkova J, et al. The combined status of ATM and p53 link tumor development with therapeutic response. Genes Dev 2009;23:1895-909.

88. Calin GA, Croce CM. Chronic lymphocytic leukemia: interplay between noncoding RNAs and protein-coding genes. Blood, 2009;114:4761-70.

89. Visone R, Rassenti LZ, Veronese A, et al. Karyotype-specific microRNA signature in chronic lymphocytic leukemia. Blood 2009;114:3872-9.

90. Mraz M, Malinova K, Kotaskova J, et al. miR-34a, miR-29c and miR-17-5p are downregulated in CLL patients with TP53 abnormalities. Leukemia 2009;23:115963.

91. Rossi S, Shimizu M, Barbarotto E, et al. microRNA fingerprinting of CLL patients with chromosome $17 p$ deletion identify a miR-21 score that stratifies early survival. Blood 116:945-52.

92. Pekarsky Y, Santanam U, Cimmino A, et al. Tcll expression in chronic lymphocytic leukemia is regulated by miR-29 and miR181. Cancer Res 2006;66:11590-3.

93. Fabbri M, Bottoni A, Shimizu M, et al. Association of a microRNA/TP53 feedback circuitry with pathogenesis and outcome of B-cell chronic lymphocytic leukemia. Jama 2011;305:59-67.

94. Dijkstra MK, van Lom K, Tielemans D, et al. 17p13/TP53 deletion in B-CLL patients is associated with microRNA-34a downregulation. Leukemia 2009;23:625-7.

95. Zenz T, Mohr J, Eldering E, et al. miR-34a as part of the resistance network in chronic lymphocytic leukemia. Blood 2009;113;3801-8. 
96. Asslaber D, Piñón JD, Seyfried I, et al. microRNA-34a expression correlates with MDM2 SNP309 polymorphism and treatment-free survival in chronic lymphocytic leukemia. Blood 115:4191-7.

97. Fong CT, Dracopoli NC, White PS, et al. Loss of heterozygosity for the short arm of chromosome 1 in human neuroblastomas: correlation with $\mathrm{N}$-myc amplification. Proc Natl Acad Sci U S A 1989;86:3753-7.

98. Rigaud G, Moore PS, Zamboni G, et al. Allelotype of pancreatic acinar cell carcinoma. Int J Cancer 2000;88:772-7.

99. Genuardi M, Tsihira H, Anderson DE, Saunders GF. Distal deletion of chromosome Ip in ductal carcinoma of the breast. Am J Hum Genet 1989;45:73-82.

100. Fang W, Piao Z, Simon D, et al. Mapping of a minimal deleted region in human hepatocellular carcinoma to $1 \mathrm{p} 36.13$ p36.23 and mutational analysis of the RIZ (PRDM2) gene localized to the region. Genes Chromosomes Cancer 2000;28:269-75.

101. Wozniak A, Sciot R, Guillou L, et al. Array CGH analysis in primary gastrointestinal stromal tumors: cytogenetic profile correlates with anatomic site and tumor aggressiveness, irrespective of mutational status. Genes Chromosomes Cancer 2007;46;261-76.

102. Leister I, Weith A, Brüderlein S, et al. Human colorectal cancer: high frequency of deletions at chromosome 1p35. Cancer Res 1990;50:7232-5.

103. Lodygin D, Tarasov V, Epanchintsev A, et al. Inactivation of miR-34a by aberrant CpG methylation in multiple types of cancer. Cell Cycle 2008;7:2591-600.

104. Li Y, Guessous F, Zhang Y, et al. MicroRNA-34a inhibits glioblastoma growth by targeting multiple oncogenes. Cancer Res 2009;69:7569-76.

105. Wiggins JF, Ruffino L, Kelnar K, et al. Development of a lung cancer therapeutic based on the tumor suppressor microRNA-34. Cancer Res 2010;70:592330.

106. Ji Q, Hao X, Zhang M, et al. MicroRNA miR-34 inhibits human pancreatic cancer tumor-initiating cells. PLoS One, 2009;4:e6816.

107. Cardinaud B, Moreilhon C, Marcet B, et al. miR-34b/miR-34c: a regulator of TCL1 expression in 11q- chronic lymphocytic leukaemia? Leukemia 2009;23:2174-7.

108. Calin GA, Dumitru CD, Shimizu M, et al. Frequent deletions and down-regulation of micro- RNA genes miR15 and miR16 at $13 q 14$ in chronic lymphocytic leukemia. Proc Natl Acad Sci U S A 2002;99:15524-9.

109. Cimmino A, Calin GA, Fabbri M, et al. miR-15 and miR-16 induce apoptosis by targeting BCL2. Proc Natl Acad Sci U S A 2005;102:13944-9.

110. Bichi R, Shinton SA, Martin ES, et al. Human chronic lymphocytic leukemia modeled in mouse by targeted TCL1 expression. Proc Natl Acad Sci U S A 2002;99:6955-60.

111. Pekarsky Y, Koval A, Hallas C, et al. Tcl1 enhances Akt kinase activity and mediates its nuclear translocation. Proc Natl Acad Sci U S A 2000;97:3028-33.

112. Park SY, Lee JH, Ha M, et al. miR-29 miRNAs activate p53 by targeting p85 alpha and CDC42. Nat Struct Mol Biol 2009;16:23-9.

113. Eis PS, Tam W, Sun L, et al. Accumulation of miR-155 and BIC RNA in human B cell lymphomas. Proc Natl Acad Sci USA 2005;102:3627-32.

114. Yamanaka Y, Tagawa H, Takahashi N, et al. Aberrant overexpression of microRNAs activate AKT signaling via down-regulation of tumor suppressors in natural killer-cell lymphoma/leukemia. Blood 2009;114:3265-75.

115. Costinean S, Zanesi N, Pekarsky Y, et al. Pre-B cell proliferation and lymphoblastic leukemia/high-grade lymphoma in E(mu)-miR155 transgenic mice. Proc Natl Acad Sci U S A 2006;103:7024-9.

116. Costinean S, Sandhu SK, Pedersen IM, et al. Src homology 2 domain-containing inositol-5-phosphatase and CCAAT enhancer-binding protein beta are targeted by miR-155 in B cells of Emicro-MiR155 transgenic mice. Blood, 2009. 114(7): p. 1374-82.

117. Costinean S, Sandhu SK, Pedersen IM, et al. Onco-miR-155 targets SHIP1 to promote TNFalpha-dependent growth of $B$ cell lymphomas. EMBO Mol Med 2009;1: 288-95.

118. Miletic AV, Anzelon-Mills AN, Mills DM, et al. Coordinate suppression of B cell lymphoma by PTEN and SHIP phosphatases. J Exp Med 207:2407-20.

119. Vargova K, Curik N, Burda P, et al. MYB transcriptionally regulates the miR-155 host gene in chronic lymphocytic leukemia. Blood 2011;117:3816-25.

120. Yin Q, Wang X, McBride J, et al. B-cell receptor activation induces $\mathrm{BIC} / \mathrm{miR}-155$ expression through a conserved AP-1 element. J Biol Chem, 2008;283:2654-62.

121. Brosh R, Shalgi R, Liran A, et al. p53Repressed miRNAs are involved with E2F in a feed-forward loop promoting proliferation. Mol Syst Biol 2008;4:229.

122. Gironella M, Seux M, Xie MJ, et al. Tumor protein 53-induced nuclear protein 1 expression is repressed by miR-155, and its restoration inhibits pancreatic tumor development. Proc Natl Acad Sci U S A 2007;104:16170-5.
123. Dillhoff M, Liu J, Frankel W, et al. MicroRNA-21 is overexpressed in pancreatic cancer and a potential predictor of survival. J Gastrointest Surg 2008;12: 2171-6.

124. Iorio MV, Ferracin M, Liu CG, et al. MicroRNA gene expression deregulation in human breast cancer. Cancer Res 2005;65:7065-70.

125. Markou A, Tsaroucha EG, Kaklamanis L, et al. Prognostic value of mature microRNA-21 and microRNA-205 overexpression in non-small cell lung cancer by quantitative real-time RT-PCR. Clin Chem 2008;54:1696-704.

126. Li J, Huang H, Sun L, et al. MiR-21 indicates poor prognosis in tongue squamous cell carcinomas as an apoptosis inhibitor. Clin Cancer Res 2009;15:3998-4008.

127. Slaby 0, Svoboda M, Fabian P, et al. Altered expression of miR-21, miR-31, miR-143 and miR-145 is related to clinicopathologic features of colorectal cancer. Oncology 2007;72:397-402.

128. Moriyama T, Ohuchida K, Mizumoto K, et al. MicroRNA-21 modulates biological functions of pancreatic cancer cells including their proliferation, invasion, and chemoresistance. Mol Cancer Ther 2009;8:1067-74.

129. Medina PP, Nolde M, Slack FJ. OncomiR addiction in an in vivo model of microRNA-21-induced pre-B-cell lymphoma. Nature 467:86-90.

130. Krichevsky AM, Gabriely G. miR-21: a small multi-faceted RNA. J Cell Mol Med 2009;13:39-53.

131. Wang P, Zou F, Zhang X, et al. microRNA21 negatively regulates $\mathrm{Cdc} 25 \mathrm{~A}$ and cell cycle progression in colon cancer cells. Cancer Res, 2009;69:8157-65.

132. Frankel LB, Christoffersen NR, Jacobsen A, et al. Programmed cell death 4 (PDCD4) is an important functional target of the microRNA miR-21 in breast cancer cells. J Biol Chem, 2008;283:102633 .

133. Asangani IA, Rasheed SA, Nikolova DA, et al. MicroRNA-21 (miR-21) post-transcriptionally downregulates tumor suppressor Pdcd4 and stimulates invasion, intravasation and metastasis in colorectal cancer. Oncogene 2008;27:2128-36.

134. Liu M, Wu H, Liu T, et al. Regulation of the cell cycle gene, BTG2, by miR-21 in human laryngeal carcinoma. Cell Res 2009;19:828-37.

135. Meng F, Henson R, Wehbe-Janek H, et al. MicroRNA-21 regulates expression of the PTEN tumor suppressor gene in human hepatocellular cancer. Gastroenterology 2007;133:647-58.

136. Meng F, Henson R, Wehbe-Janek H, et al. Identification of BTG2, an antiprolifera- 
tive p53-dependent component of the DNA damage cellular response pathway. Nat Genet 1996;14:482-6.

137. Rouault JP, Falette N, Guéhenneux F, et al. PTEN tumor suppressor regulates p53 protein levels and activity through phosphatase-dependent and -independent mechanisms. Cancer Cell 2003;3:117-30.

138. Busino L, Chiesa M, Draetta GF, Donzelli M. Cdc25A phosphatase: combinatorial phosphorylation, ubiquitylation and proteolysis. Oncogene 2004;23:2050-6.

139. Reinhardt HC, Aslanian AS, Lees JA, Yaffe MB. p53-deficient cells rely on ATM- and ATR-mediated checkpoint signaling through the p38MAPK/MK2 pathway for survival after DNA damage. Cancer Cell 2007;11:175-89.
140. Carracedo A, Pandolfi PP. The PTEN-PI3K pathway: of feedbacks and cross-talks. Oncogene 2008;27:527-41.

141. Stambolic V, MacPherson D, Sas D, et al. Regulation of PTEN transcription by p53. Mol Cell 2001;8:317-25.

142. Redondo-Muñoz J, Escobar-Díaz E, Hernández Del Cerro M, et al. Induction of B-chronic lymphocytic leukemia cell apoptosis by arsenic trioxide involves suppression of the phosphoinositide 3kinase/Akt survival pathway via c-junNH2 terminal kinase activation and PTEN upregulation. Clin Cancer Res 2010;16: 4382-91.

143. Shehata M, Schnabl S, Demirtas D, et al., Reconstitution of PTEN activity by CK2 inhibitors and interference with the PI3-
K/Akt cascade counteract the antiapoptotic effect of human stromal cells in chronic lymphocytic leukemia. Blood 2010;116: 2513-21.

144. Stilgenbauer S, Eichhorst BF, Busch R, et al. Biologic and clinical markers for outcome after fludarabine (F) or $\mathrm{F}$ plus cyclophosphamide (FC): Comprehensive analysis of the CLL4 trial of the GCLLSG. Blood 2008;112:2089.

145. Stilgenbauer S, Zenz T, Winkler D, et al. Genomic aberrations, VH mutation status and outcome after fludarabine and cyclophosphamide (FC) or FC plus rituximab (FCR) in the CLL8 trial. Blood 2008;112:781. 